\title{
PENGGUNAAN TANAMAN AIR (BAMBU AIR DAN MELATI AIR) PADA PENGOLAHAN AIR LIMBAH PENYAMAKAN KULIT UNTUK MENURUNKAN BEBAN PENCEMAR DENGAN SISTEM WETLAND DAN ADSORPSI
}

\section{THE USE OF AQUATIC PLANTS (Equisetum hyemale and Echinodorus palaef) IN TANNERY WASTEWATER TREATMENT TO REDUCE POLLUTANT LOAD WITH WETLAND AND ADSORPTION SYSTEM}

\author{
Sri Sutyasmi*, Heru Budi Susanto \\ Balai Besar Kulit, Karet, dan Plastik, Yogyakarta \\ *E-mail: srisutyasmi@ymail.com
}

Diterima: 15 Juli 2013 Direvisi: 21 September 2013 Disetujui: 2 Oktober 2013

\begin{abstract}
Wastewater treatment using wetland and adsorption system were carried out to improve the properties of secondary settling pond's outlet. The purpose of this research was to reduce pollutant level from the secondary settling pond's outlet so it could be used in the wetland stage and the treated wastewater could be reused. Wastewater effluent from secondary settling pond was discharged into adsorber and subsequently into wetland by flow rate arrangement. Laboratory simulation was carried out to find out the capacity of aquatic plants in reducing the pollutant level. The result showed that the BOD, COD and TSS value of wastewater from laboratory simulation were 191 $\mathrm{mg} / \mathrm{l}, 6.24 \mathrm{mg} / \mathrm{l}$, and $24 \mathrm{mg} / \mathrm{l}$, and after the wetland stage were $409 \mathrm{mg} / \mathrm{l}, 10.32 \mathrm{mg} / \mathrm{l}$, and $145 \mathrm{mg} / \mathrm{l}$ respectively. The quality of wastewater met the standard SNI 06-0649-1989 Water for tannery.
\end{abstract}

Keywords: adsorption, aquatic plant, wastewater treatment, wetland

\begin{abstract}
ABSTRAK
Pengolahan air limbah dengan sistem wetland dan adsorpsi merupakan teknik pengolahan air limbah lanjutan dari bak pengendap II untuk memperbaiki kualitas air limbah yang keluar dari bak pengendap tersebut. Tujuan penelitian adalah untuk menurunkan beban pencemar dari bak pengendap II agar bisa masuk ke sistem wetland (agar tanaman tidak mati) dan air limbah hasil perlakuan bisa digunakan kembali. Air limbah yang keluar dari bak pengendap II dimasukkan ke bak adsorpsi dan selanjutnya dialirkan ke wetland dengan pengaturan debit. Untuk mengetahui sampai seberapa jauh tanaman air bisa menurunkan beban pencemar maka perlu dibuat percobaan simulasi skala Laboratorium. Hasil uji kualitas air limbah hasil simulasi menunjukkan bahwa Biological Oxygen Demand (BOD), Chemical Oxygen Demand (COD) dan Total Suspended Solids (TSS) berturut-turut sebesar $191 \mathrm{mg} / 1 ; 6,24 \mathrm{mg} / \mathrm{l}$; dan $24 \mathrm{mg} / 1$ sedangkan sesudah melalui sistem wetland berturut-turut $409 \mathrm{mg} / 1 ; 10,32 \mathrm{mg} / \mathrm{l}$; dan $145 \mathrm{mg} / \mathrm{l}$. Hasil uji kualitas air hasil percobaan memenuhi persyaratan dalam SNI 06-0649-1989 tentang Air untuk penyamakan kulit.
\end{abstract}

Kata kunci: adsorpsi, tanaman air, pengolahan air limbah, wetland 


\section{PENDAHULUAN}

Air merupakan sumber daya pokok untuk proses penyamakan kulit karena jumlah penggunaan air untuk proses sangat besar dan harus memenuhi syarat baku mutu air untuk proses penyamakan kulit. Air limbah yang dihasilkanpun cukup besar dan sangat potensial mencemari lingkungan. Pengolahan air limbah kulit biasanya terdiri atas pengolahan primer, sekunder dan dilanjutkan pengolahan tersier apabila kualitas air limbah masih belum memenuhi ketentuan yang berlaku. Hasil uji pengolahan air limbah kulit yang keluar dari bak pengendap II pada IPAL industri penyamakan kulit kadang-kadang mutunya masih jelek, yang disebabkan oleh kapasitas berlebihan dan pengolahan yang kurang baik dan benar. Untuk itu diperlukan sistem pengolahan lanjut (advanced wastewater treatment). Pengolahan limbah cair lanjutan yang banyak diteliti diantaranya adalah sistem rawa buatan (constructed wetland) dan adsorpsi.

Construted wetland adalah lahan basah buatan sebagai tempat untuk pengolahan limbah yang merupakan suatu proses pengolahan limbah dengan meniru berlangsungnya proses penjernihan air di lahan basah alami atau rawa. Di rawa tumbuhan air (hidrophita) memiliki peran penting dalam proses pemulihan kualitas air limbah secara alamiah (Vymazal, 2009). Aktivitas pengolahan unsur hara yang diambil dari air limbah inilah yang dimasak oleh pigmen daun (klorofil) agar tanaman menjadi tumbuh, baik secara fisik maupun jumlah tunasnya dan sekaligus mengurangi pencemar dalam air limbah (Truu et al., 2009).

Jenis tumbuhan atau tanaman dapat disesuaikan dengan jenis sistem wetland yang digunakan. Pada subsurface flow wetland, air tidak menggenang di atas media tanam, tetapi air mengalir di bawah media tanam sehingga memiliki berbagai keuntungan. Salah satu keuntungannya adalahtanamandapatberadaptasi lebihbervariasi sehinggadapatdigunakansebagai taman estetika (Vymazal, 2009). Tanaman yang telah diteliti penggunaannya dalam wetland antara lain Phagmites australis, Typha latifolia, Scirpus (Bulrush), Alisma plantago (Alfous et al., 2010), Cyperus alternifolius, Typha latifolia (Leto et al., 2013) dan lain-lain.
COD yang berhubungan dengan zat yang terendapkan (settleable solids) di dalam air buangan dihilangkan melalui sedimentasi. COD terlarut dan dalam bentuk koloid yang masih tersisa dalam larutan dapat dihilangkan melalui aktivitas metabolisme dan interaksi kimia fisika didalam zona perakaran/matrik substrat(Danista, 2012). Media ini berfungsi sebagai penunjang struktur bakteri seperti halnya pengganti sistem aerator mekanik dalam transfer oksigen dalam sistem pengolahan air buangan. Pengurangan BOD dengan menggunakan proses ini bisa mencapai $65 \%$ sampai dengan $85 \%$. Padatan tersuspensi dapat dikurangi sebanyak $90 \%$, sedangkan pengurangan nutrien (nitrogen dan fosfor) dapat mencapai $85 \%$ serta pengurangan organisme patogen mencapai 99,5\% (Durai, 2011).

Tidak seperti rawa alami, rawa buatan untuk pengolahan air limbah dapat dibuat hampir dimana saja meskipun dengan lahan yang terbatas. Rawa buatan juga mempunyai kapasitas dan kemampuan pengolahan air limbah yang lebih bagus dibandingkan dengan rawa alami karena bagian dasar dari rawa buatan ini biasanya dibuat dengan konstruksi khusus dan dapat diatur pembebanan hidrolisnya (Lee, 2009). Parameter desain yang sangat penting untuk sistem constructed wetland adalah waktu detensi hidrolis (4-15 hari), kedalaman basin (panjang dan lebar), laju beban $\mathrm{BOD}_{5}$, dan laju beban hidrolis (Metcalf and Eddy, 2001).

Adsorpsi secara umum adalah proses penggumpalan bahan padat terlarut (soluble solid) pada bahan cair, oleh permukaan zat atau bahan penjerap melalui ikatan fisika-kimia antara bahan tersuspensi dengan penjerapnya (Mufrodi, 2008).

Salah satu adsorben yang biasa digunakan dalam pengolahan air minum dan juga air limbah adalah karbon aktif atau arang aktif. Arang aktif digunakan untuk penghilangan bau (Chen et al., 2013), warna (Nonpui et al., 2010) dan ion-ion logam berat (Lo et al., 2012). Karena merupakan fenomena permukaan maka makin luas permukaan kontaknya makin tinggi efisiensi penjerapannya (Suardana, 2008). Syarat ini dapat dipenuhi oleh arang yang sudah diaktifkan agar bersifat porous dan kaya saluran kapiler. Arang yang belum aktif ditandai oleh 
saluran kapilernya tertutup oleh pengotor baik dalam bentuk bahan organik maupun anorganik (Kemala et al., 2006).

Tujuan penelitian adalah untuk menurunkan beban pencemar air limbah penyamakan kulit yang keluar dari bak pengendap II dengan sistem wetland dan adsorpsi, agar air limbah terolah bisa digunakan kembali untuk penyamakan kulit. Sebagai parameter keberhasilan pengolahan air limbah tersebut digunakan parameter mutu yang tercantum dalam SNI 06-0649-1989 tentang air untuk penyamakan kulit (BSN, 1989).

\section{BAHAN DAN METODE \\ Bahan Penelitian}

Bahan Penelitian adalah tanaman melati air (Equisetum hyemale) dan bambu air (Echinodorus palaef), air limbah kulit yang keluar dari bak pengendap II dari salah satu industri kulit di Yogyakarta, alumunium sulfat, polielektrolit, dan karbon aktif.

\section{Peralatan Penelitian}

Peralatan penelitian terdiri atas rangkaian alat untuk simulasi di laboratorium seperti disajikan pada Gambar 1. Aplikasi hasil simulasi dilakukan di bak adsorpsi dan wetland yang terlihat pada Gambar 2.

Dari Gambar 1 alur kerjanya adalah sebagai berikut: air limbah kulit yang keluar dari industri penyamakan kulit berturut-turut dialirkan ke bak homogenisasi, bak koagulasi dan flokulasi, bak pengendap I, bak aerasi, bak pengendapan

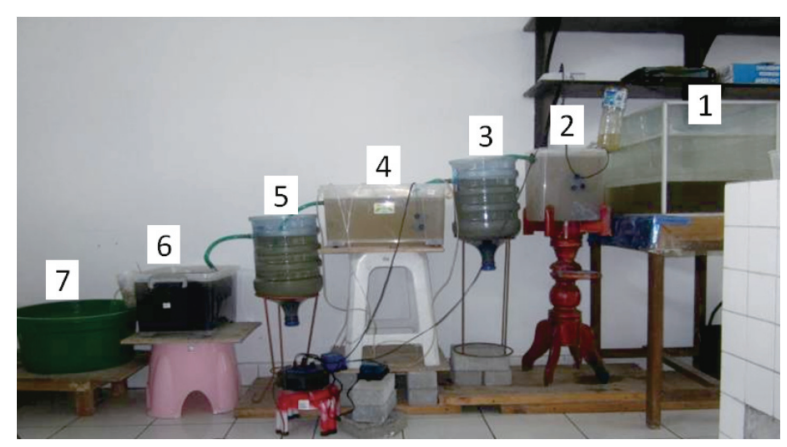

Gambar 1. Rangkaian simulasi untuk pengolahan air limbah skala laboratorium: (1) bak homogenisasi, (2) bak flokulasi dan koagulasi, (3) bak pengendap I (clarifier I), (4) bak biologi/ aerasi, (5) bak pengendap II (clarifier II), (6) bak adsorpsi/saringan pasir, (7) bak wetland
II, bak adsorpsi, bak wetland dan terakhir di bak penampung air limbah terolah.

\section{Metode Penelitian}

Untuk menurunkan beban pencemar air limbah yang keluar dari bak pengendap II maka air limbah yang keluar dari bak pengendap II dialirkan menuju bak saringan pasir (bak adsorpsi) terlebih dahulu dengan pengaturan debit, agar waktu tinggal dalam bak saringan pasir/adsorpsi cukup memadai. Selanjutnya air limbah di alirkan ke wetland (rawa buatan).

Untuk bisa diterapkan dengan baik di Instalasi Pengolahan Air Limbah (IPAL) maka perlu dibuat simulasi skala laboratorium terlebih dahulu seperti ditampilkan pada Gambar 1. Simulasi skala laboratorium untuk mengolah air limbah dari industri penyamakan kulit digunakan sistem koagulasi dan flokulasi dengan dosis yang benar (3- 5\%) alum dan 0,5\% polielektrolit. Air limbah diendapkan di bak pengendap I (clarifier I), kemudian dilanjutkan dengan pengolahan sekunder (pengolahan biologi) dengan sistem aerasi dan diendapkan pada bak pengendap II (clarifier II). Air limbah yang keluar dari bak pengendap II selanjutnya dialirkan ke bak saringan pasir atau bak adsorpsi dengan debit 15 $\mathrm{ml} /$ menit agar waktu tinggal cukup memadai. Selanjutnya dialirkan ke bak wetland dengan debit yang sama.

Air limbah yang keluar dari bak pengendap II dan bak adsorpsi diuji BOD,COD dan TSS dengan metode uji sesuai dengan metode uji Standard Method yaitu masing-masing dengan winkler methods, refluks methods dan gravimetri.

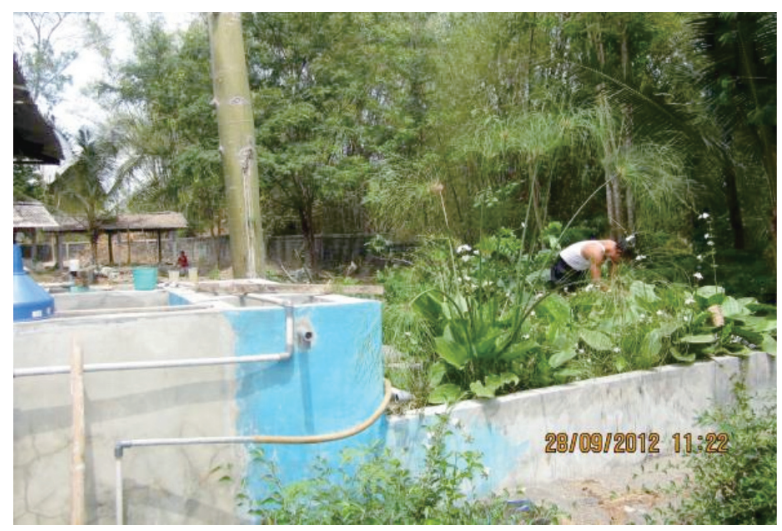

Gambar 2. Gambar bak saringan pasir dan wetland 
Sedangkan air limbah terolah yang keluar dari bak wetland diuji $\mathrm{Fe}, \mathrm{NaCl}$, Bilangan $\mathrm{KMnO}_{4}$, kekeruhan dan $\mathrm{pH}$ sesuai dengan SNI 060649-1989 tentang baku mutu air untuk proses penyamakan kulit.

\section{HASIL DAN PEMBAHASAN \\ Hasil Uji Air Limbah dari IPAL Industri Kulit Sebelum Diperbaiki.}

Mutu air limbah hasil pengolahan yang keluar dari bak pengendap II ditandai oleh konsentrasi bahan pencemar relatif masih tinggi, sehingga perlu perbaikan dan pengolahan lanjut. Hal ini disebabkan karena volume air limbah yang masuk ke IPAL melebihi kapasitas, sebagai akibat banyaknya kulit yang diolah dan konsekuensinya air limbah yang dihasilkan juga banyak, sehingga pengolahan air limbah tidak efektifdan efisien. Oleh sebab itu perlu perbaikan kualitas air limbah dengan membangun bak saringan pasir/adsorpsi. Tabel 1 adalah hasil uji air limbah dari bak pengendap II dan saringan pasir yang diatur dengan debit $50 \mathrm{ml} /$ menit.

Tabel 1 menunjukkan bahwa hasil uji air limbah yang keluar dari bak pengendap II (BOD, COD dan TSS) relatif masih tinggi. Untuk itu diperlukan upaya untuk mengatasinya agar dapat diperoleh mutu air limbah yang baik. Dari hasil uji air limbah yang keluar dari saringan pasir diketahui bahwa mutu air limbah hasil uji air limbah dengan debit $50 \mathrm{ml} /$ menit (BOD,COD dan TSS) masih relatif tinggi, sehingga perlu penambahan waktu tinggal yang cukup di bak saringan pasir tersebut, dengan cara menurunkan debit air limbah yang masuk ke bak saringan pasir. Simulasi pengolahan air limbah dibuat dan disesuaikan dengan pengolahan (IPAL)

Tabel 1. Hasil uji air limbah kulit dari bak pengendap II dan saringan pasir sebelum pengaturan debit dan setelah pengaturan debit 50 ml per menit

\begin{tabular}{ccc}
\hline \multirow{2}{*}{ Parameter } & \multicolumn{2}{c}{ Hasil uji IPAL industri kulit } \\
\cline { 2 - 3 } & $\begin{array}{c}\text { Luapan } \\
\text { pengendap II }\end{array}$ & $\begin{array}{c}\text { Luapan } \\
\text { saringan pasir }\end{array}$ \\
\hline BOD (mg/l) & 960,2 & 621,5 \\
COD (mg/l) & 1557,7 & 1276,68 \\
TSS (mg/l) & 276,0 & 135,0 \\
\hline
\end{tabular}

yang ada di industri kulit agar hasil simulasi dapat dipakai sebagai pemandu untuk perbaikan mutu air limbah di industri kulit.

\section{Hasil Uji Mutu Air Limbah Hasil Simulasi Skala Laboratorium}

Hasil uji mutu air limbah hasil simulasi seperti disajikan pada Tabel 2. Tabel 2 menunjukkan bahwa mutu air limbah dengan pengolahan baik dan benar mampu menurunkan beban pencemar (BOD: 99,35\%, COD : 87,73\%, dan TSS: 91,30\%) dan mutu air limbah industri kulit dapat memenuhi persyaratan yang berlaku yaitu sesuai dengan yang tercantum pada SNI06-0649-1989. Penurunan beban pencemar ini melebihi angka yang dikemukakan oleh Sulawesty dkk. (2010), yaitu penurunan BOD, COD, dan TSS dengan sistem wetland berturutturut sebesar $45-95 \%, 15-75 \%$, dan 34-95\%. Penurunan kadar bahan pencemar organik terlarut dibantu oleh bakteri aerobik heterofilik dengan persamaan reaksi sebagai berikut (Vymazal and Kröpfelová, 2009):

$$
\mathrm{C}_{6} \mathrm{H}_{12} \mathrm{O}_{6}+\underset{6 \mathrm{O}_{2} \rightarrow}{6 \mathrm{CO}_{2}}+6 \mathrm{H}_{2} \mathrm{O}+12 \mathrm{e}^{-}+\text {energi }
$$

\section{Hasil Uji Mutu Air Limbah yang Keluar dari Bak Adsorpsi}

Setelah mengalami perbaikan sistem pengolahan, maka perlakuan air limbah kulit disesuaikan dengan sistem simulasi skala laboratorium, yaitu dengan mengurangi debit dari $50 \mathrm{ml} /$ menit menjadi $15 \mathrm{ml} /$ menit dan pemberian alum serta polielektrolit yang cukup ( $4 \%$ alum dan $0,5 \%$ polielektrolit) pada IPAL industri penyamakan kulit. Diperoleh hasil uji mutu air limbah yang keluar dari bak

Tabel 2. Hasil uji simulasi di laboratorium sesudah wetland dengan debit $15 \mathrm{ml} /$ menit.

\begin{tabular}{ccc}
\hline \multirow{2}{*}{ Parameter } & \multicolumn{2}{c}{$\begin{array}{c}\text { Hasil uji simulasi di labora- } \\
\text { torium }\end{array}$} \\
\cline { 2 - 3 } & influen & efluen \\
\hline BOD (mg/l) & 960,2 & 6,24 \\
COD (mg/l) & 1557,7 & 191 \\
TSS (mg/l) & 276,0 & 24 \\
\hline
\end{tabular}


Tabel 3. Hasil uji mutu air limbah penyamakan kulit di IPAL sesudah disesuaikan dengan hasil simulasi skala laboratorium

\begin{tabular}{cccccccc}
\hline \multirow{2}{*}{$\begin{array}{c}\text { Parameter mutu } \\
\text { air limbah }\end{array}$} & \multicolumn{2}{c}{$\begin{array}{c}\text { Luapan } \\
\text { pengendap II }\end{array}$} & \multicolumn{2}{c}{$\begin{array}{c}\text { Luapan saringan } \\
\text { pasir/adsorbsi }\end{array}$} & \multicolumn{2}{c}{$\begin{array}{c}\text { Jumlah penurunan } \\
(\%)\end{array}$} \\
\cline { 2 - 8 } & i & ii & i & ii & i & ii \\
\hline BOD (mg/l) & 960,2 & 290 & 621,50 & 120 & 69,79 & 85,47 \\
COD (mg/l) & 1557,70 & 479,36 & 1276,8 & 185,50 & 69,22 & 80,69 \\
TSS (mg/l) & 473 & 276 & 147,50 & 135 & 42,64 & 8,47 \\
\hline
\end{tabular}

Keterangan: (i) hasil uji mutu air limbah sesudah bak pengendap II dan bak adsorpsi, sebelum menerapkan hasil simulasi, (ii) hasil uji mutu air limbah dari bak pengendap II dan bak adsorpsi sesudah menerapkan hasil simulasi.

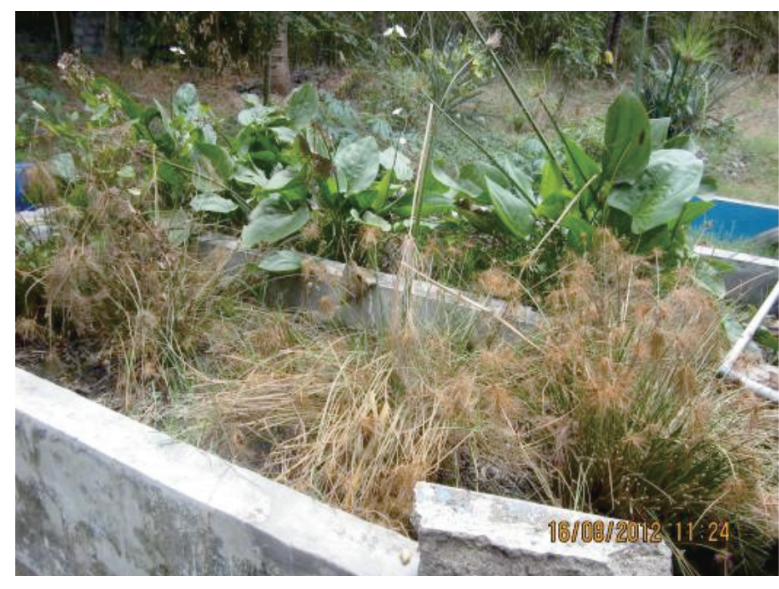

(a)

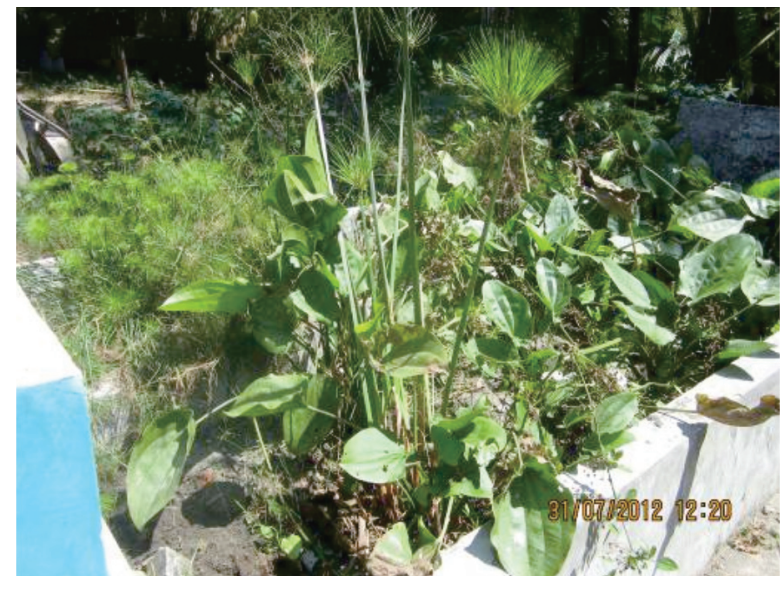

(b)

Gambar 3. Tanaman melati air dan bambu air: (a) mati, (b) hidup

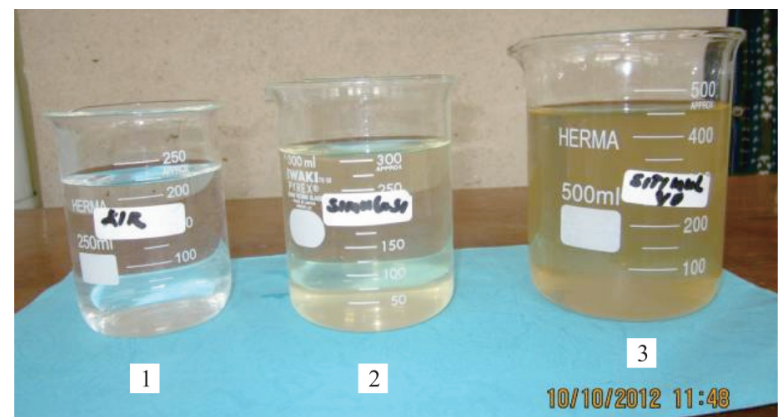

Gambar 4. Perbandingan air (1) Air sumur (2) Air limbah terolah hasil simulasi (3) Air limbah terolah yang keluar dari wetland

adsorpsi jauh lebih baik dari sebelumnya. Hal ini menunjukkan bahwa air limbah sejelek apapun asal diolah dengan baik dan benar dapat dihasilkan air limbah dengan mutu baik. Hasil uji mutu air limbah dapat dilihat pada Tabel 3,

Tabel 3 menunjukkan bahwa konsentrasi pencemar di IPAL mengalami perbaikan mutu dimana konsentrasi pencemar dari bak pengendap II setelah mengalami perbaikan terjadi penurunan beban pencemar. Dengan demikian dapat dikatakan bahwa penggunaan simulasi skala laboratorium di IPAL industri kulit bermanfaat memperbaiki mutu air limbah yang ada di industri penyamakan kulit.

Air limbah yang keluar dari bak adsorpsi selanjutnya dialirkan ke bak wetland dengan debit $15 \mathrm{ml} /$ menit agar tanaman tidak mati, dan mutu air limbah menjadi baik karena waktu tinggal di wetland cukup memadai yaitu sekitar 4-15 hari. Gambar 3(a) menunjukkan bahwa tanaman mati karena dampak dari kandungan bahan pencemar masih tinggi dan Gambar 3(b) menunjukkan bahwa tanaman tetap hidup karena waktu tinggal dari air limbah yang telah baik mutunya cukup lama.

Untuk mengetahui mutu air limbah hasil olahan baik dari hasil simulasi skala laboratorium maupun dari bak wetland IPAL dan dibandingkan dengan air kran dapat dilihat pada Gambar 4. Gambar 4 menunjukkan bahwa 
air limbah hasil pengolahan di IPAL masih agak keruh walaupun hasil uji mutu air limbah sudah baik. Hal ini kemungkinan karena penggunaan arang batok sebagai adsorben untuk pengolahan air limbah ikut tersuspensi dalam air limbah sehingga air limbah menjadi keruh. Terdapat kombinasi aktifitas fisika, kimia, dan biologi yang mempengaruhi kinerja wetland yang terjadi pada media tumbuh tanaman dalam wetland dan mikrobia, dan sedimen yang terbentuk (Le et al., 2009). Air limbah hasil olahan terbukti dapat digunakan kembali untuk keperluan penyamakan kulit, dan uji mutu air limbah hasil pengolahan di dasarkan ketentuan dalam SNI-06-0649-1989 tentang air untuk proses penyamakan kulit.

\section{Hasil Uji Mutu Air Limbah Industri Penyamakan Kulit Sesudah Dilewatkan dalam Wetland.}

Hasil uji mutu simulasi skala laboratorium menunjukkan bahwa BOD, COD, dan TSS dari efluen relatif rendah sehingga dapat diterapkan di IPAL industri penyamakan kulit. Berdasarkan hasil penerapan penyesuaian debit air limbah dan kadar alum serta polielektrolit, maka dihasilkan mutu air limbah dari industri penyamakan kulit seperti terlihat pada Tabel 4.

Tabel 4. Hasil uji mutu air limbah industri penyamakan kulit sesudah penerapan hasil simulasi pada wetland

\begin{tabular}{cc}
\hline Parameter mutu limbah & Hasil uji \\
\hline BOD $(\mathrm{mg} / \mathrm{l})$ & 10,32 \\
COD $(\mathrm{mg} / \mathrm{l})$ & 409 \\
TSS $(\mathrm{mg} / \mathrm{l})$ & 145 \\
\hline
\end{tabular}

Tabel 4 menunjukkan bahwa konsentrasi pencemar pada air limbah yang keluar dari wetland sudah rendah sehingga hasil simulasi tersebut berhasil diterapkan di IPAL industri penyamakan kulit.

\section{Hasil Uji Mutu Air Limbah Menurut Ketentuan dalam SNI 06-0649-1989}

Tabel 5 menunjukkan bahwa air limbah kulit yang sudah diolah baik melalui simulasi maupun di industri kulit, hampir semua sampel memenuhi persyaratan, kecuali kekeruhan air limbah yang diolah di industri kulit, sedikit melebihi persyaratan $(69,2 \mathrm{mg} / \mathrm{l})$ yang seharusnya tidak boleh melebihi $50 \mathrm{mg} / \mathrm{l}$.

Menurut Hidayah dan Aditya (2010), penurunan konsentrasi bahan organik dalam sistem wetland terjadi karena adanya mekanisme aktivitas mikroorganisme dan tanaman, melalui proses oksidasi bakteri aerob yang tumbuh disekitar rhizosphere tanaman. Mekanisme penurunan biologi terjadi karena aktifitas mikrobiologi di akar. Akar tanaman meningkatkan kepadatan dan aktivitas mikroba yang disediakan oleh permukaan akar untuk pertumbuhan mikrobia (Vymazal 2008).

\section{KESIMPULAN DAN SARAN \\ Kesimpulan}

Penggunaan tanaman air untuk pengolahan air limbah dengan sistem wetland dan adsorpsi dapat menurunkan beban pencemar BOD, COD dan TSS berturut-turut sebesar 98,92\%, 73,74\% dan $69,34 \%$ dengan hasil uji BOD, COD dan TSS berturut-turut sebesar 10,32 mg/l; 409 $\mathrm{mg} / \mathrm{l}$ dan $145 \mathrm{mg} / \mathrm{l}$. Mutu air limbah hasil

Tabel 5. Hasil uji mutu air limbah hasil pengolahan untuk proses penyamakan kulit dan persyaratannya.

\begin{tabular}{lcccc}
\hline \multirow{2}{*}{ Parameter mutu air } & \multicolumn{2}{c}{ Hasil uji } & \multicolumn{2}{c}{ Persyaratan } \\
\cline { 2 - 5 } & $\begin{array}{c}\text { Air limbah terolah } \\
\text { industri kulit }\end{array}$ & $\begin{array}{c}\text { Air limbah hasil simulasi } \\
\text { skala laboratorium }\end{array}$ & Minimum & Maksimum \\
\hline Kesadahan (Derajat Jerman) & 0,0488 & 0,0355 & - & 12,0 \\
Kadar besi (mg/l) & 2,67 & 1,66 & - & 50,0 \\
NaCL (mg/l) & 0,29 & 0,38 & - & 100,0 \\
Bilangan Permanganat/ & 4,8 & 4,1 & - & 5,0 \\
KMnO4 (mg/l) & & & - & 50,0 \\
Kekeruhan (mg/l) & 69,2 & 47,6 & 6 & 7,5 \\
pH & 7,5 & 7,5 & & \\
\hline
\end{tabular}


pengolahan menggunakan sistem wetland dan adsorpsi dapat memenuhi persyaratan SNI 060649-1989, yaitu tentang mutu air untuk proses penyamakan kulit.

\section{Saran}

Perlu penelitian tentang mikrobia apa yang menyerap bahan pencemar.

\section{UCAPAN TERIMA KASIH}

Peneliti mengucapkan terima kasih kepada bapak Widodo dan Wahono dan seluruh tim yang telah membantu dalam pelaksanaan penelitian sampai selesai.

\section{DAFTAR PUSTAKA}

Afrous, A., Hedayat, N., Liaghat, A., Mohammadpour, M., and Manshouri, M., 2010. Accumulation and uptake of nitrogen and phosphorus by four species of aquatic plants under arid and semi-arid conditions of Dezful, Iran, World Applied Sciences Journal, 10(8): 886-891.

BSN (Badan Standardisasi Nasional), 1989. SNI 06-0649-1989 Air untuk Proses Penyamakan Kulit Samak Nabati.

Chen, J.,Pan, X., andChen, J., 2013. Regeneration of activated carbon saturated with odors by non-thermal plasma, Chemosphere, 92(6): 725-730.

Danista, R. W., 2012. Penggunaan bambu air (Equisetum hyemale) dan bamboo rejeki (Dracaena sonderiana) untuk penyisihan Nitrogen dan fosfor pada grey water dengan system constructed wetland, Skripsi, Institut Teknologi Sepuluh Nopember.

Durai, G. and Rajasimman, M., 2011. Biological treatment of tannery wastewater-A review, Journal of Environmental Science and Technology, 4(1): 1-17.

Hidayah, E. N. dan Aditya W., 2010. Potensi dan pengaruh tanaman pada pengolahan air limbah domestik dengan sistem constructed wetland, Envirotek: Jurnal Ilmiah Teknik Lingkungan, 2(2): 11-18.

Kemala, T., Sjahriza, A., dan Puspitasari, D.P., 2006. Adsorpsi karbon aktif termodifikasizink klorida terhadap surfaktan anionik pada berbagai $\mathrm{pH}$, Prosiding Seminar Nasional HKI 2006, Bogor.
Lee, C. G., Fletcher, T. D., and Sun, G., 2009. Nitrogen removal in constructed wetland systems, Engineering in Life Sciences, 9(1): 11-22.

Leto, C., Tuttolomondo, T., La Bella, S., Leone, R., and Licata, M., 2013. Effects of plant species in a horizontal subsurface flow constructed wetland-phytoremediation of treated urban wastewater with Cyperus alternifolius and Typha latifolia in the West of Sicily (Italy), Ecological Engineering, 61: 282-291.

Lo, S. F., Wang, S. Y., Tsai, M. J., and Lin, L. D., 2012. Adsorption capacity and removal efficiency of heavy metal ions by Moso and Ma bamboo activated carbons, Chemical Engineering Research and Design, 90(9): 1397-1406.

Metcalf and Eddy, 2001. Wastewater engineering: Treatment and reuse, 4th ed., McGraw-Hill, New York.

Mufrodi, Z., Widiastuti, N., dan Kardika, R. C., 2008. Adsorpsi zat warna tekstil dengan menggunakan abu terbang (fly ash) untuk variasi massa adsorben dan suhu operasi, Prosiding Seminar Nasional Teknoin, Bidang Teknik Kimia dan Tekstil, Yogyakarta

Noonpui, S., Thiravetyan, P., Nakbanpote, W., and Netpradit, S., 2010. Color removal from water-based ink wastewater by bagasse fly ash, sawdust fly ash and activated carbon, Chemical Engineering Journal, 162(2): 503-508.

Suardana, I. N., 2008. Optimasi daya adsorpsi zeolit terhadap ion krom (III), Jurnal Penelitian dan Pengembangan Sain dan Humaniora, 2(1): 17-33.

Sulawesty, F., Haryani, G. S., dan Widiyanto, T., 2010. Pengembangan teknologi lahan basah buatan untuk restorasi sungai, Workshop Citarum River Restoration Using Alternative Technology, Bandung.

Truu, M., Juhanson, J., and Truu, J., 2009. Microbial biomass, activity, and community composition in constructed wetlands, Science of The Total Environment, 407: 3958-3971. 
Vymazal, J., 2009. The use constructed wetlands with horizontal subsurface flow for various types of wastewater, Ecological Engineering, 35: 1-17.

Vymazal, J. and Kröpfelová, L., 2009. Removal of organics in constructed wetlands with horizontal sub-surface flow: A review of the field experience, Science of the total environment, 407(13): 3911-3922. 